ORIGINAL ARTICLE

ARTIGO ORIGINAL

\title{
Unveiling atopic dermatitis burden in Brazil: a report from clinical assistance perspective
}

\author{
Revelando a dermatite atópica no Brasil: um \\ relato da perspectiva da assistência clínica
}

Kleyton Mesquita' ${ }^{1}$ Mariana Colombini², Gleison Duarte ${ }^{3}$, Sineida Berbert Ferreira4, Ariana Yang ${ }^{5}$, Marcia Mallozi ${ }^{6}$, Omar Lupi ${ }^{7}$, Marta Guidacci ${ }^{8}$, Daniel Abreu${ }^{9}$, Helder Paiva ${ }^{10}$

DOI: $10.21115 /$ JBES.v11.n2.p153-60

\section{Keywords:}

atopic dermatitis, atopic eczema, burden, quality of life, costs, treatment

\section{Palavras-chave:}

dermatite atópica, eczema atópico, carga, qualidade de vida, tratamento

\begin{abstract}
Objective: Atopic dermatitis (AD) or atopic eczema is a chronic skin inflammatory disease that involves the interaction between immune, genetic and environmental triggers. AD affects 15\%$20 \%$ of infants and $1 \%-4 \%$ of adults worldwide although prevalence varies per country. The main objective is to raise the awareness of AD impact on patients' quality of life (QoL) in Brazil. Methods: Interviews were carried out with key Therapeutic Area Experts (TAEs) throughout the country to gain information about disease management, treatment efficacy and patient's QoL. For disease cost estimation, private health costs from public sources was used. Results: AD prevalence in adults was estimated at 7\% in Brazil, of which 35\% was moderate and 30\% severe AD. Overall, $41 \%$ of patients have undergone 5 or more different treatments. However, $17 \%$ and $29 \%$ of patients with moderate and severe $A D$, respectively, fail to control their disease. Emollients and topical steroids are the main first-line $(1 \mathrm{~L})$ treatments for all $A D$ patients, although in the case of moderate and severe AD, a rapid 2 -week treatment transition from $1 \mathrm{~L}$ to $2 \mathrm{~L}$ has been reported. In terms of economic burden, for severe and moderate AD patients, direct medical costs (medical appointments, treatments, hospitalizations and others) are between 94\% and 93\%. Regarding indirect costs, absenteeism was estimated to be responsible for $6 \%$ and $7 \%$ of total cost in moderate and severe AD patients, respectively. Conclusion: There is a need for $A D$ treatments that can be used in the long term without severe side effects and with a positive impact on QoL.
\end{abstract}

\section{RESUMO}

Objetivo: A dermatite atópica (DA) ou eczema atópico é uma doença inflamatória que envolve a interação entre fatores imunológicos, genéticos e ambientais. A DA afeta 15\% a 20\% das crianças e $1 \%$ a $4 \%$ dos adultos. O objetivo é conscientizar sobre o impacto da DA na qualidade de vida (QdV) dos pacientes no Brasil. Métodos: Entrevistas foram conduzidas com Especialistas dessa Área Terapêutica (EATs) em todo o país para obter informações sobre o manejo da doença, eficácia do tratamento e QdV dos pacientes. Para estimativa dos custos da doença, utilizamos custos da saúde privada de fontes públicas. Resultados: A prevalência de DA em adultos foi estimada em 7\% no Brasil, dos quais 35\% possuem DA moderada e 30\%, severa. No geral, $41 \%$ dos pacientes foram submetidos a cinco ou mais tratamentos diferentes. No entanto, $17 \%$ e $29 \%$ dos pacientes com DA moderada/ grave, respectivamente, não conseguem controlar sua doença. Emolientes e esteroides tópicos são

Received on: 08/05/2019. Approved for publication on: 08/23/2019.

1. Advanced Institute on Plastic Surgery and Dermatology (IACD), Brasília, DF, Brazil.

2. Dermatologist member of the Scientific Committee of Association of Support to Atopic Dermatitis, São Paulo, SP, Brazil.

3. Member of Brazilian Dermatology Society (SBD) and Group for Research and Assessment of Psoriasis and Psoriatic Arthritis (GRAPPA), Salvador, BA, Brazil.

4. Center for Dermatology Studies in Paraná and Member of Brazilian Dermatology Society, International fellow at American Academy of Dermatology, Maringá, PR, Brazil.

5. Hospital das Clínicas, Universidade de Campinas (Unicamp), Brazilian Association of Allergy and Immunology (ASBAI), Campinas Allergy Institute (IAC), Campinas, SP, Brazil.

6. Immunologist/Allergologist member of Brazilian Association of Allergy and Immunology (ASBAI), São Paulo, SP, Brazil.

7. Hospital Universitário Clementino Fraga Filho (HUCFF); Former SBD (Brazilian Dermatology Society) president, Rio de Janeiro, RJ, Brazil.

8. MD, Hospital de Base, Brazilian Association of Allergy and Immunology (ASBAI), Brasília, DF, Brazil.

9. MD, Medical Affairs, Sanofi Genzyme, São Paulo, SP, Brazil.

10. Phd Immunology, Market Access, Sanofi, São Paulo, SP, Brazil.

Location where study was done: LSC Consulting and Sanofi, São Paulo/Brazil.

Conflict of interests: Sanofi supported in the funding of the study, but the authors and contributors did not receive honoraria in conjunction with authorship and are not employees of Sanofi.

Corresponding author: Helder Paiva. Av. das Nações Unidas, 14401, Brooklin, São Paulo, SP, Brazil. CEP: 04794-000. Telephone:

+55 (11) 94506-9575. E-mail: helder.paiva@sanofi.com 
os principais tratamentos de primeira linha (1L) para todos os pacientes. No caso de DA moderada/ grave, a transição rápida do tratamento de $1 \mathrm{~L}$ para $2 \mathrm{~L}$ em duas semanas é relatada. Em termos de carga econômica, para pacientes com DA grave e moderada, entre 94\% e 93\% são custos médicos diretos (consultas médicas, tratamentos, hospitalizações e outros). Considerando custos indiretos, 0 absenteísmo é responsável por 6\% e 7\% do custo total em pacientes com DA moderada e grave, respectivamente. Conclusão: Em conclusão, há necessidade de tratamentos de DA que possam ser usados a longo prazo sem efeitos colaterais graves e com impacto positivo na qualidade de vida.

\section{Introduction}

Atopic dermatitis (AD) or atopic eczema is a chronic inflammatory disease common to the skin. It involves a form of interaction between the immune-mediated, genetic and environmental triggers (Arkwright et al., 2013, Eichenfield 2004, Eichenfield et al., 2003, Eichenfield et al., 2014a, Eichenfield et al., 2014b). AD affects between 15\% and 20\% of children and $1 \%$ to $4 \%$ of adults worldwide (Barbarot et al., 2018, Eichenfield et al., 2014b, Nutten, 2015) although the prevalence per country can vary significantly. Even in patients in whom the clinical presentation is mild, the burden of the disease can be considerable (Ellis et al., 2012).

As in other regions, the incidence of atopic dermatitis in Latin America has been increasing in recent years (Sánchez et al., 2014). In Brazil, AD prevalence is estimated based on the International Study of Asthma and Allergies in Childhood (ISAAC) questionnaire (Yamada et al., 2002), suggesting a cumulative prevalence between $11.7 \%$ and $13.8 \%$ for children (6-12 years) (Yamada et al., 2002). Another study indicated a mean prevalence of $8.9 \%$ for eczema and $4.4 \%$ for severe eczema (Solé et al., 2006).

$A D$ is a common condition in infancy but reduces around age 3 in a significant proportion of children (Illi et al., 2004). The prognosis is mostly determined by severity and presence of atopic sensitization. Patients generally outgrow the disease in the last stage of childhood, and about $70 \%$ of patients who had $A D$ since their childhood have a spontaneous remission of the disease before adolescence (Abuabara et al., 2018; Illi et al., 2004). However, for adults, AD can be a much more serious condition characterized by chronic, thick, red and lichenified lesions (Eichenfield et al., 2014b). Patients may experience acute, vesicular or suppurating outbreaks. Pruritus is intense and strongly affects daily life, sleep and activity of adult patients (Arkwright et al., 2013). AD affects different parts of the body in adults compared to children, commonly the hands and face. Even when AD is a mild clinical disease in adults, the psychosocial and economic burden of the disease can be profound (Ellis et al., 2012). In cases of atypical presentations or unresponsiveness to treatments, alternative diagnoses should be considered (Arkwright et al., 2013).

Relatively little has been published on adult $A D$ compared to the body of literature devoted to AD in children, even though adults with severe AD are greatly affected by the disease (Ellis et al., 2012). Due to the prevalence and its high burden on the quality of life, it is important that patients treat this disease adequately (Nutten, 2015). One of the biggest challenges is the management of patients with moderate-to-severe AD because, although there are few treatment options currently available, most patients remain inadequately controlled and, therefore, must endure difficulties that undermine their quality of life.

\section{Objective}

The main objective of this paper is to raise awareness of the frequency and impact of $A D$ on the quality of life of patients in Brazil.

\section{Methods}

Data was collected through interviews with key Therapeutic Area Experts (TAEs) throughout Brazil to obtain information about their management of the disease, their perception of the efficacy of current treatments and how $A D$ affects the patient's Quality of Life (QoL). We invited 10 experts with much experience in the treatment of $A D$, some of them, members of the Association of Support to Atopic Dermatitis, Brazilian Society of Dermatology or developers of local guidelines for AD. All invited TAEs agreed to participate.

A standardized survey was developed with specific questions about the diagnosis of the disease, the treatment algorithm, the TAEs perception about the implications of AD on quality of life (QoL) of patients and the unmet needs related to the treatment of the disease. The questionnaire was endorsed by the external experts and finalized in an iterative process.

Each TAE separately participated in a structured face-toface interview of 60-80 minutes. The questions considered required quantitative responses in $80 \%$ of the cases and qualitative responses in the remaining $20 \%$. The quantitative responses were analyzed to reach consensus in the different topics addressed, while the qualitative responses were examined, in terms of words or phrases most commonly used, to identify the main causes of the differences found in the data. The results shown in this study are mainly the weighted average of TAEs responses to quantitative questions.

Interviewees were informed that their names would not be used in any report or dissemination of results without their consent. Each section was reviewed by at least two authors, and then a final version was approved by all participants, using the Delphi methodology to achieve consensus.

For the cost estimation, we used private costs taken from public sources: Classificação Brasileira Hierarquizada de 
Procedimentos Médicos (CBHPM) (AMB, 2016), Câmara de Regulação do Mercado de Medicamentos (CMED) (Anvisa, 2016) and Mean Daily Wage in Brazil (IBGE, 2016).

\section{Results}

\section{Atopic dermatitis in Brazil}

AD prevalence is estimated at 7\% in Brazil for adults regardless of the severity, according to the experts interviewed. Moreover, TAEs estimate that, in 2017 alone, 181 new cases of AD were diagnosed in adults. $A D$ is diagnosed mainly through clinical symptoms and, in the case of Brazil, standardized criteria are also used. There is a consensus among the experts about the best criteria; $82 \%$ use Hanifin and Rajka (Hanifin \& Reed, 2007). In only $8 \%$ of the cases, other criteria are used, and in the remaining $10 \%$ of the cases, there are no criteria being used. The level of severity of the disease is methodologically classified as well. In $82 \%$ of the cases, experts assess AD severity based on the SCOring Atopic Dermatitis index (SCORAD), 16\% TAEs use Eczema Area and Severity Index (EASI), and in $2 \%$ of the cases, severity is not classified using standardized criteria. From the universe of patients treated by the TAEs interviewed, it is estimated that 35\% present mild AD, 35\% moderate AD and 30\% severe AD.

\section{Treatment schemes}

Emollients and topical steroids are the main first-line (1L) treatments for all AD patients. Although in the case of moderate and severe $A D$ a rapid 2-week treatment transition from $1 \mathrm{~L}$ to $2 \mathrm{~L}$ has been reported due to topical corticosteroids (CT), there is a lack of efficacy to improve and maintain symptoms. Furthermore, in 74\% of severe AD patients, systemic treatments, such as oral steroids, cyclosporine, and methotrexate are prescribed as $2 \mathrm{~L}$ treatments (second line) (Figure 1).
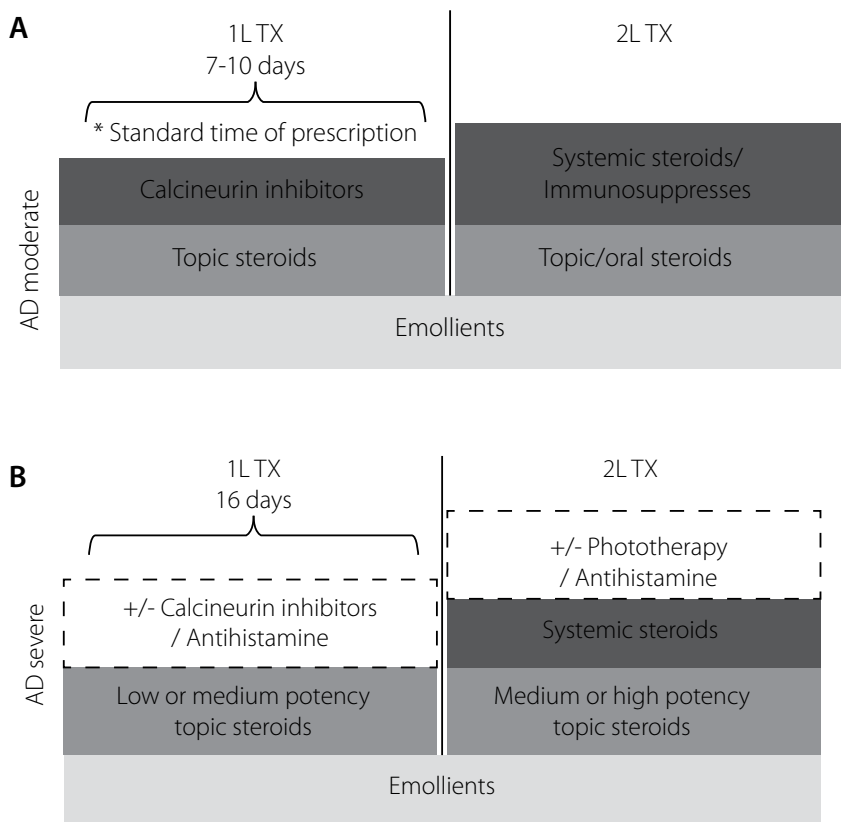

Figure 1. Duration of treatment in patients whose first-line treatment was topical steroids.
Overall, $41 \%$ of patients have undergone 5 or more different treatments. For severe diagnosed AD patients, 5 or more treatments were reported in $82 \%$ for this subpopulation (Figure 2A). Disease evolution and treatment failure to previous therapies were the most commonly reported causes of different treatment lines (Figure 2B).

A) Treatments used by severity

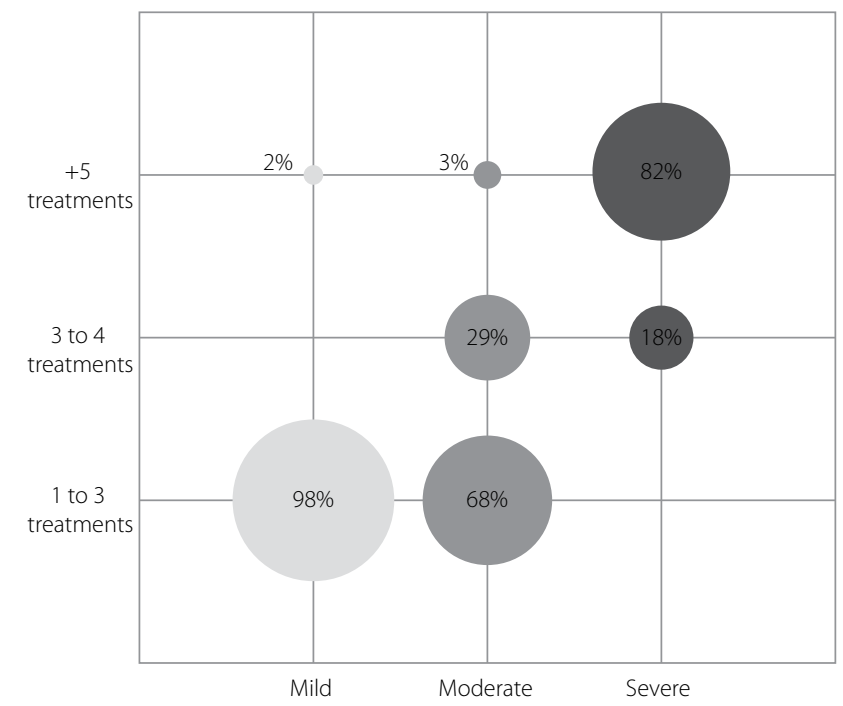

B) Main reasons for the use of different treatments

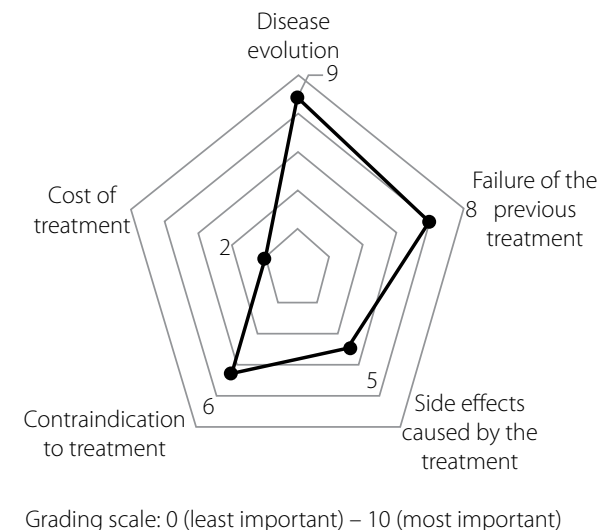

Figure 2. Number of different treatments used by AD severity (A) and its causes (B).

Despite the availability of diverse treatment options, several patients fail to control their disease. The TAEs estimate that $8 \%$ of patients with mild AD are not under control, while this percentage rises to $17 \%$ and $29 \%$ for patients with moderate and severe AD, respectively (Figure 3A). Altogether the intake of higher $\mathrm{CT}$ dosage than prescribed by the treating physician was reported in $27 \%$ of moderate AD patients and up to $42 \%$ for severe AD patients (Figure $3 B$ ).

Flares are an important factor to be taken under consideration for $A D$ patients. It impacts treatment lines and disease control management. In one year, $42 \%$ of severe $A D$ patients have more than 10 flares per year, with a median duration of 12 days or more (Figure 4). Patients who experience 
flares need long-term disease control treatments. Experts reported off-label methotrexate as the most prescribed treatment for long-term use (3-6 months) for patients with moderate and severe AD. On average, TAEs reported that flares are controlled in 3 days. All TAEs interviewed prescribe topical steroids alone or in combination during the flarefree periods, in $43 \%$ of the cases, TAEs use a combination of topical steroids and topical calcineurin inhibitors.

Considering currently available pharmacological treatments, TAEs agree that, for moderate AD patients, $2 \mathrm{~L}$ and third line (3L) treatments are barely sufficient to cover the clinical needs of their patients, while for severe patients the available treatments are considered not sufficient in any of the treatment lines. The treatment efficacy listed in order of importance are reduction in pruritus severity, reduction in the score of the tests (SCORAD, EASI, POEM) and reduction in the extent of the affected area (Figure 5).
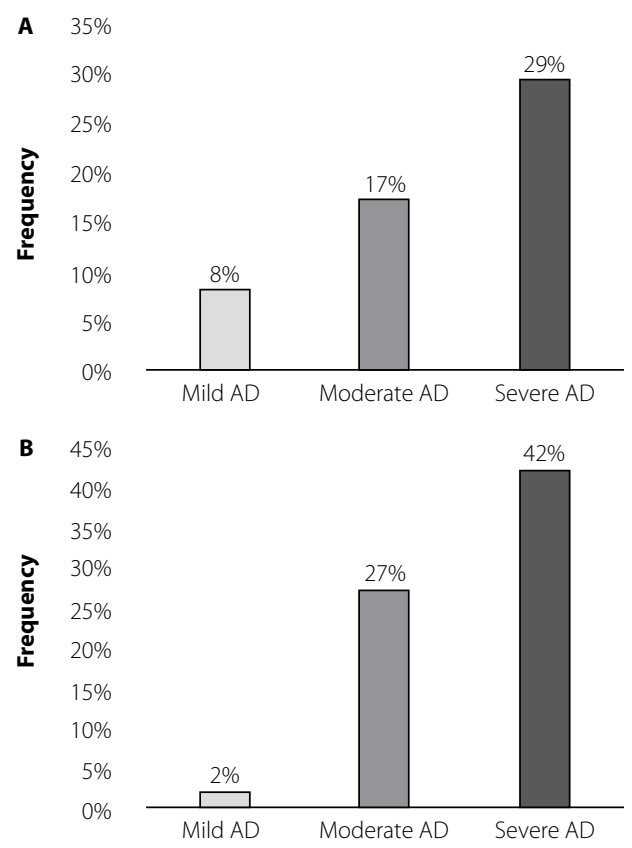

Figure 3. Failures of treatments. A) Percentage of uncontrolled patients by severity. B) Patients' topical corticosteroids higher dosage intake reported by treating physicians.

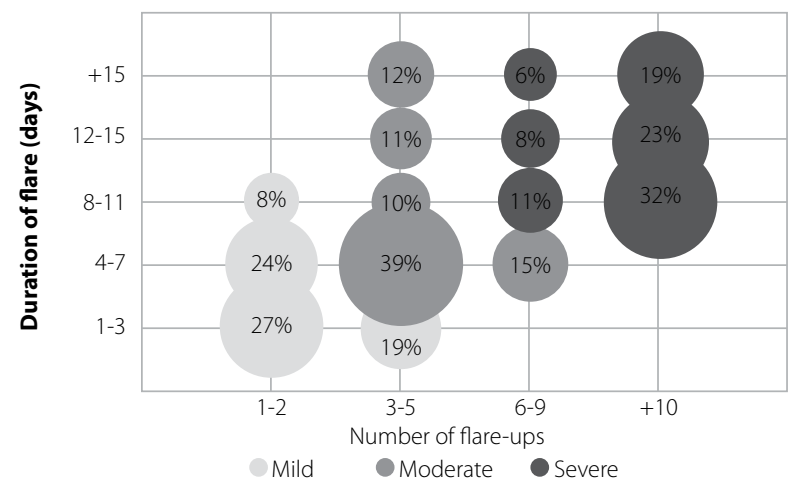

Figure 4. Distribution of patients (\%) by number and duration of flares during a 1-year period.

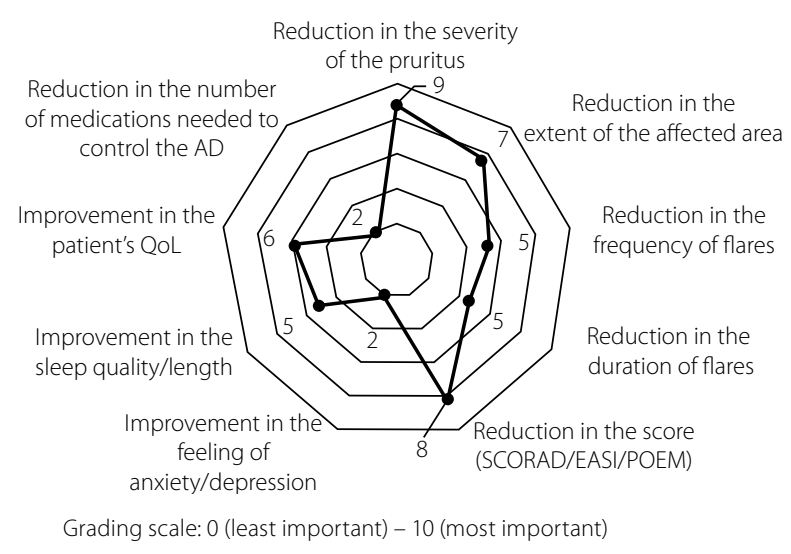

Figure 5. Weight of key elements to consider a pharmacological treatment efficient.

\section{Impact on Quality of Life (QoL)}

Given all the unmet medical needs reported above and especially the need to address new treatment options to target moderate-to-severe $A D$, the expert panel reinforces AD has a strong impact on patient QoL. QoL is also the most important factor along with pain related to symptom severity (Figure 6). AD affects the patient's quality of life mainly by interfering with their daily activities and generating shame or low self-esteem, as perceived by TAEs interviewed. In $1 \%$ of the cases, AD condition can even lead patients up to suicidal ideation. Additionally, TAEs agree that current pharmacological treatments are not enough to address a better QoL for the AD patient, as described below.

\section{Burden of $A D$}

In terms of economic burden, it is undeniable that treatment, general measures, hospitalization and absenteeism, among other factors, imply a great expense for patients and society. It is not an easy task to estimate the costs associated with the disease; therefore, there is a lack of reliable information about the economic burden of AD. Nevertheless, an analysis was performed to assess such costs, based on the treatment and usage of resources described by TAEs using private publicly available information. There is no consensus on the treatment algorithm to be followed; therefore, a weighted average of the treatment cost is calculated in order to estimate the average annual cost to treat AD by severity as shown for mild Patients. Cost of treatment is indicated as the main barrier faced by patients with $A D$ in following their treatment, along with the fear of side effects.

Our analysis indicates that, for severe and moderate $A D$ patients, between $94 \%$ and $93 \%$ of the cost is due to direct medical costs (diagnosis tests, physician's scheduled and unscheduled visits, treatment, hospitalizations, side effects monitoring and complications) (Table 1). Treatment cost represents the greatest proportion of total direct medical costs; it represents $48 \%, 57 \%$ and $82 \%$ for severe, moderate and mild patients, respectively. 
A

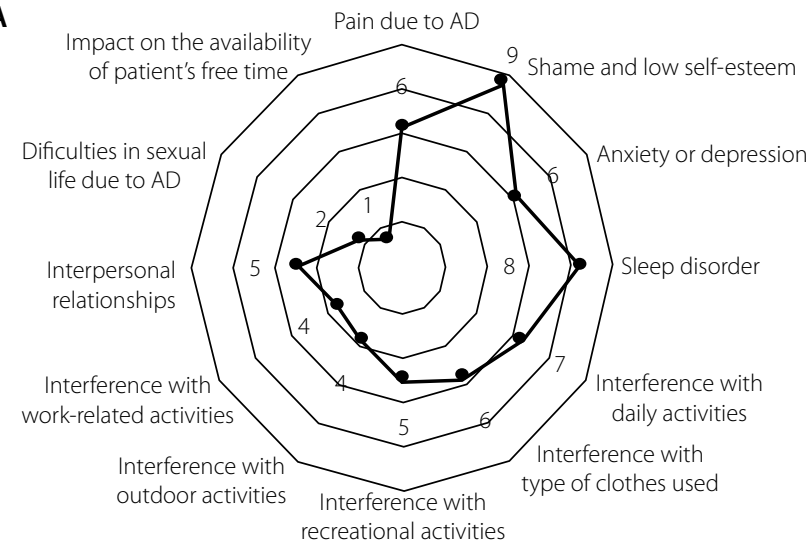

B

Experience of pain

Sensation of shame and low self-esteem

Anxiety or depression

Sleep disorders

Interference with daily activities

Interference with type of clothes used

Interference with recreational activities

Interference with outdoor activities

Interference with work-related activities

Interpersonal relationships

Difficulties in sexual life due to $A D$

Impact on the availability of patient's free time

Figure 6. A) Main QoL factors impacted by AD according to TAEs perception. B) If current available pharmacological treatments are enough to ensure the improvement of the patient's QoL.

Table 1. Economic burden by AD severity

\begin{tabular}{|c|c|c|c|c|}
\hline \multicolumn{2}{|c|}{$\begin{array}{l}\text { Average annual costs per } \\
\text { patient }\end{array}$} & Mild AD & $\begin{array}{c}\text { Moderate } \\
\text { AD }\end{array}$ & $\begin{array}{c}\text { Severe } \\
\text { AD }\end{array}$ \\
\hline & Total & $4,436.4$ & $5,697.9$ & $13,027.2$ \\
\hline \multirow{7}{*}{$\begin{array}{l}\text { Direct } \\
\text { costs }\end{array}$} & Diagnostic tests & 21.7 & 21.7 & 21.7 \\
\hline & $\begin{array}{c}\text { Medical } \\
\text { appointments } \\
\text { with } \\
\text { dermatologists }\end{array}$ & 663.8 & $1,029.5$ & $1,155.1$ \\
\hline & $\begin{array}{l}\text { Medical } \\
\text { appointments } \\
\text { with other } \\
\text { specialties }\end{array}$ & 0.0 & 40.1 & 53.5 \\
\hline & Treatments & $3,624.5$ & $3,229.5$ & $6,258.6$ \\
\hline & Hospitalization & 0.0 & 29.9 & $3,914.3$ \\
\hline & Side effects & 0.0 & 957.4 & 957.4 \\
\hline & $\begin{array}{c}\text { Complications/ } \\
\text { infections }\end{array}$ & 126.3 & 389.8 & 666.6 \\
\hline $\begin{array}{l}\text { Indirect } \\
\text { cost }\end{array}$ & Absenteeism & 6.6 & 414.1 & 880.9 \\
\hline \multicolumn{2}{|c|}{ Total costs } & $4,443.0$ & $6,112.0$ & $13,908.1$ \\
\hline
\end{tabular}

For social burden, absenteeism from work or daily activities among AD patients was estimated (Figure $7 \mathrm{~A}$ ) to be $21 \%$ and $32 \%$ for those with moderate $A D$ and severe $A D$, respectively. Altogether with the economic burden described previously, $A D$ patients face comorbidities that are not included in the cost analysis but, in the case of rhinitis, affect up to $57 \%$ of the patients, with asthma affecting 34\% (Figure 7B), while nonfood allergies, such as contact allergies, happen in $23 \%$ of the patients. Additionally, to the use of emollients or moisturizers, general counseling about the use of non-allergenic soaps and special care while bathing is also recommended by the TAE considered. Thus, an AD patient has not only the burden of the cost of the pharmacological treatment but also the cost and time associated with correctly following such general measures.

\section{Discussion}

Atopic dermatitis is a complex disorder caused by the interplay between multiple genetic and environmental factors (Arkwright et al., 2013; Eichenfield et al., 2014). Particularly in patients with severe disease, the effect is not just an itchy rash but also the secondary effects on the psychological well-being of the patient and their caregivers, particularly disturbed sleep (Arkwright et al., 2013).

A

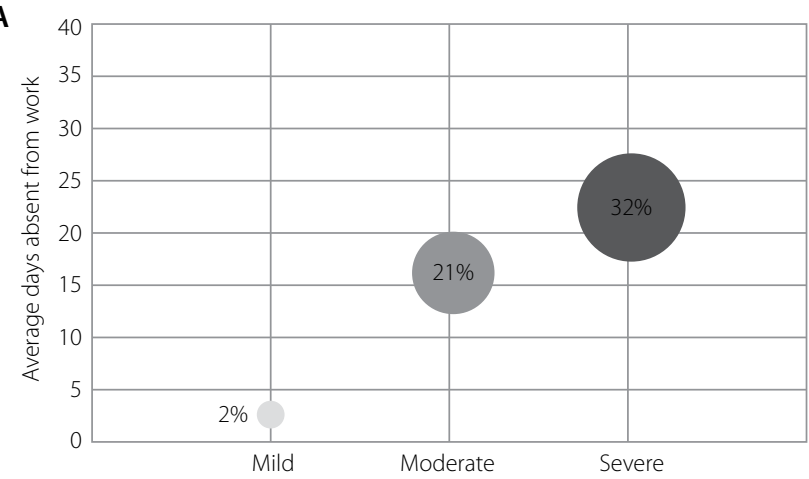

B

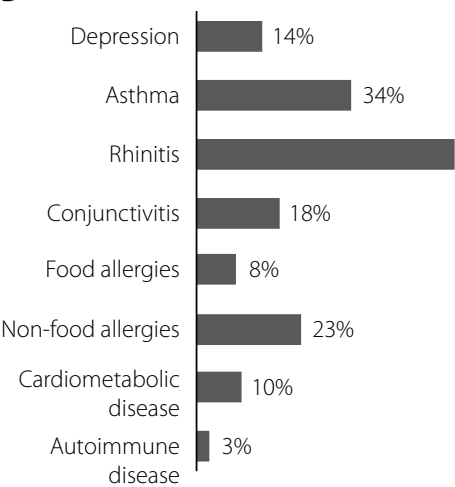

Additional treatments

- Anxiolytics, Antidepressants

- Inhaled steroids,

Bronchodilators, Biological

$57 \% \cdot$ Inhaled steroids,

Antihistamine

- Antihistamine

- Antihistamine, Allergy immunotherapy

- Specific tx for hypertension $\&$ diabetes

- Specific tx for vitiligo and hypothyroidism

Figure 7. A) Percentage of patients absent from their work. B) Percentage of patients facing comorbidities. 
As in other regions, the incidence of atopic dermatitis in Latin America has been increasing in recent years (Sánchez et al., 2014). There is limited information about AD in Brazil and prior research studies are mostly limited to the pediatric population (Alvarenga \& Caldeira, 2009; Bertanha et al., 2016). Worldwide, there are also limited reported data in $A D$ for Latin America (Sánchez et al., 2014); therefore, this report aims to create awareness of AD management in the country and the impact on patient's QoL. Also, this study aims to provide suggestions for future research that specifically overcome the limitations of the current document.

This project is limited to therapeutic area experts' impressions based on their clinical practice and experience from all over the country. The results of the project may be biased by the location (Salvador, Rio de Janeiro, Brasília, Maringá, São Paulo and Ribeirão Preto) of the selected experts. TAEs were selected based on their expertise in disease management and research experience. TAEs responses during interviews are subject to bias, considering that the form used was not previously validated. Experts may have a biased perception of AD distribution by severity; their patients may consist of a higher proportion of AD moderateto-severe patients than the overall AD population.

Economic burden, as analyzed in this project, considers direct costs such as treatment cost, laboratory tests, monitoring of complications and also indirect costs such as absenteeism. The economic burden faced by AD patients may differ from the results presented in this project as other elements are considered.

While much is known about the diagnosis and evaluation of $A D$, much has yet to be learned since there are significant gaps in the validation of AD diagnostic criteria, development, severity and quality of life measurements (Eichenfield et al., 2014b). Before embarking on AD treatment regimes, the diagnosis should be confirmed. Also, AD severity should be recorded at each visit to provide an objective assessment of response to treatment schemes (Arkwright et al., 2013). None of the systemic treatment schemes have on label indications for AD, but they have long clinical usage and application in international guidelines and consensus. Although there are several clinical guidelines, many of their recommendations cannot be universal since they depend on the characteristics of each region (Sánchez et al., 2014).

Previous studies demonstrated that AD harms the quality of life of pediatric patients and their families (Alvarenga \& Caldeira, 2009). Eczema is a major health problem worldwide, mainly in developed countries where its higher prevalence is influenced by socioeconomic and environmental factors. It is also associated with the prevalence of atopic dermatitis (Bertanha et al., 2016). Data obtained in studies of quality of life in $A D$ should be used to guide clinical practice in order to identify individual treatment strategies and should lead to the adoption of measures to reduce the impact of the disease on patients and their families (Alvarenga \& Caldeira, 2009). Also, understanding the incidence of skin diseases is fundamental in making decisions regarding allocating resources for clinical care and research (Bertanha et al., 2016).

\section{Conclusion}

Throughout this study, unmet needs have been identified. First, there have been no major studies on the economic burden of the disease for $A D$ in the country. There is a lack of awareness about the implications of AD in the patients $\mathrm{QoL}$ by service providers and public and private payers. Finally, there is a need for safe long-term treatments for AD that can provide disease control, minimizing disease burden and with a positive impact on QoL.

\section{SUPPLEMENTARY MATERIAL:}

\section{Study Guideline and Therapeutic Area Experts (TAE)}

LSC designed a Discussion Guideline, for further review with Sanofi's team, focusing on AD management, with thematic relative to:

- Patients journey by disease severity (i.e. referral process, lines of treatment, etc.);

- The use of medical resources needed to treat moderate-to-severe AD patients;

- The utilization of off-label therapies for patients inadequately controlled and reimbursement policies.

Physicians were asked to estimate possible issues faced by the patient regarding:

- Economic burden by disease severity:

- Direct costs (i.e. prescriptions, physician visits, emergency, hospital costs, over-the-counter pharmacy costs, caregivers, tests, etc.);

- Indirect costs (i.e. absenteeism).

- Quality of life, using an adaptation of the Dermatology Life Quality Index to be answered by physicians to estimate:

- Painfulness experience;

- Sensation of embarrassment or self-consciousness;

- Interference with daily activities such as shopping or gardening;

- Influence o-f the disease on the clothes worn;

- Influence of the disease on social or leisure activities;

- Repercussion of the disease on the abilities to exercise;

- Repercussion of the disease on the regular working or studying schedule;

- Problem faced with partner, friends or relatives due to the disease;

- Difficulties faced in sex life because of the disease;

- Repercussion of the treatment on the free time available. 
Regional Sanofi's Compliance Team validated the Discussion Guidelines and QoL assessment tools before performing the interviews.

\section{Target Centers and TAEs}

LSC relied on the Regional/Local Sanofi team to introduce us to desired TAEs in accordance with:

- TAEs participation on national and international published papers and guidelines;

- The participation of the Center/TAE in AD or Dupilumab clinical trials;

- Major collaborators in related medical associations (ex: Sociedad Latinoamericana de Alergia, Asma e Inmunología).

- Current Sanofi's medical panel.

It was highly desirable to include Physicians and Payers with direct experience in Patients Associations or previous Market Researches in the interviewee sample in order to guarantee proper awareness and sensitization about $A D$ burden for the patients in the national/LatAm context.

Physicians and payers were approached to explain the purpose of the study: understand current AD management, disease burden and unmet needs in LatAm. Sanofi's close participation with LSC was required to ease initial contact and communication, engagement, and proper participation in all the scheduling and assessment phases.

\section{Understanding of the LatAm overview for the Atopic Dermatitis management Objective:}

During the third step, LSC's Consultants performed interviews with physicians from selected centers to obtain information on:

- The current treatment pathways, medical resources and treatment availability;

- The access and utilization of off-label therapies;

- The financial burden associated with the disease (direct and indirect costs);

- Quality of life offered by current therapies and unmet needs;

- Limitations and potential improvements in the current treatment.

\section{Process:}

Physicians and payers accepting to participate received an invitation for the interview. Interviews lasted around 1 hour and were conducted face-to-face.

No phone interviews were performed. The list of the TAEs interviewed is presented in Table A.

Table A. Therapeutic Area Expert for Brazil

\begin{tabular}{|c|c|c|c|}
\hline Name & Location & Specialty & Institution \\
\hline Dra. Mariana Zaniboni Colombini & São Paulo & Dermatologist & $\begin{array}{l}\text { Dermatologist member of the Scientific } \\
\text { Committee of Association of Support to Atopic } \\
\text { Dermatitis }\end{array}$ \\
\hline Dr. Regis Campos & Salvador & Immunologist & Psoriasis expert \\
\hline Dr. Omar Lupi & Rio de Janeiro & Dermatologist & $\begin{array}{l}\text { Hospital Universitário Clementino Fraga Filho } \\
\text { (HUCFF); Former SBD (Brazilian Dermatology } \\
\text { Society) president }\end{array}$ \\
\hline Dr. Kleyton de Carvalho Mesquita & Brasília & Dermatologist & $\begin{array}{l}\text { AD-related papers } \\
\text { Advanced Institute on Plastic Surgery and } \\
\text { Dermatology (IACD) }\end{array}$ \\
\hline Dra. Sineida Berbert Ferreira & Maringá & Dermatologist & $\begin{array}{l}\text { Center for Dermatology Studies in Parana and } \\
\text { Member of Brazilian Dermatology Society, } \\
\text { International fellow at American Academy of } \\
\text { Dermatology }\end{array}$ \\
\hline Dr. Gleison Duarte & Salvador & Dermatologist & $\begin{array}{l}\text { Member of SBD (Brazilian Dermatology Society) } \\
\text { and GRAPPA (Group for Research and Assessment } \\
\text { of Psoriasis and Psoriatic Arthritis) }\end{array}$ \\
\hline $\begin{array}{l}\text { Dra. Marta de Fatima Rodrigues da } \\
\text { Cunha Guidacci }\end{array}$ & Brasília & Immunologist & $\begin{array}{l}\text { MD - Hospital de Base - DF, ASBAI (Brazilian } \\
\text { Association of Allergy and Immunology) }\end{array}$ \\
\hline Dra. Karla de P. Arruda & Ribeirão Preto & $\begin{array}{l}\text { Immunologist/ } \\
\text { Allergologist }\end{array}$ & Medical School of Ribeirão Preto (FMRP-USP) \\
\hline Dra. Marcia Carvalho Mallozi & São Paulo & $\begin{array}{l}\text { Immunologist/ } \\
\text { Allergologist }\end{array}$ & $\begin{array}{l}\text { Immunologist/Allergologist member of ASBAI } \\
\text { (Brazilian Association of Allergy and Immunology) }\end{array}$ \\
\hline Dra. Ariana Campos & São Paulo & $\begin{array}{l}\text { Immunologist/ } \\
\text { Allergologist }\end{array}$ & $\begin{array}{l}\text { Hospital das Clínicas (HC), Unicamp (Universidade } \\
\text { de Campinas), ASBAI (Brazilian Association of } \\
\text { Allergy and Immunology), Campinas Allergy } \\
\text { Institute (IAC) }\end{array}$ \\
\hline
\end{tabular}




\section{Identification of opportunities of the current $A D$ 's environment for the LatAm context, and National manuscript preparation \\ Objective:}

The last stream of work is the writing of the full report identifying the burden, unmet needs and opportunities of the current AD's environment in each country.

This final report aims to be used as a ground for the preparation of a manuscript for further publication in a scientific journal.

\section{Process:}

Based on the information collected during the interviews, the report will underline:

- The treatment algorithm by disease severity;

- The burden of the disease (direct cost and indirect costs faced by patients);

- Real-life issues faced by patients from physicians' point of view;

- Payers priorities over AD therapies costs, QoL burden and other unmet needs;

After validation of the findings with the local experts, the process of manuscript preparation started.

\section{Acknowledgments}

We thank Javier Pico from LifeSciences Consultants, and the physicians: Dr. Mariana Zaniboni Colombini, Dr. Regis Campos, Dr. Omar Lupi, Dr. Kleyton de Carvalho, Dr. Sineida Berbert Ferreira, Dr. Gleison Duarte, Dr. Marta de Fatima Rodrigues da Cunha Guidacci, Dr. Karla de P. Arruda, Dr. Marcia Carvalho Mallozi and Dr. Ariana Campos for the contribution to this study as experts. We also thank Cecilia Toledo and Roberta Monteiro from Sanofi for their editorial assistance on the manuscript.

\section{References}

Abuabara K, Yu AM, Okhovat JP, Allen IE, Langan SM. The prevalence of atopic dermatitis beyond childhood: A systematic review and metaanalysis of longitudinal studies. Allergy. 2018;73(3):696-704.

Alvarenga TM, Caldeira AP. Quality of life in pediatric patients with atopic dermatitis. J Pediatr (Rio J). 2009;85(5):415-20.

AMB - Associação Médica Brasileira. Classificação Brasileira Hierarquizada de Procedimentos Médicos (CBHPM). São Paulo: AMB; 2016.

Anvisa - Agência Nacional de Vigilância Sanitária. Câmara de Regulação do Mercado de Medicamentos (CMED). 2016. Available from: http://portal. anvisa.gov.br/cmed.
Arkwright PD, Motala C, Subramanian H, Spergel J, Schneider LC, Wollenberg A; Atopic Dermatitis Working Group of the Allergic Skin Diseases Committee of the AAAAl. Management of difficult-to-treat atopic dermatitis. J Allergy Clin Immunol Pract. 2013;1(2):142-51.

Barbarot S, Auziere S, Gadkari A, Girolomoni G, Puig L, Simpson EL, et al. Epidemiology of atopic dermatitis in adults: Results from an international survey. Allergy. 2018;73(6):1284-93.

Bertanha F, Nelumba EJ, Freiberg AK, Samorano LP, Festa CN. Profile of patients admitted to a triage dermatology clinic at a tertiary hospital in Sao Paulo, Brazil. An Bras Dermatol. 2016;91(3):318-25.

Eichenfield LF. Consensus guidelines in diagnosis and treatment of atopic dermatitis. Allergy. 2004;59 Suppl 78:86-92.

Eichenfield LF, Hanifin JM, Beck LA, Lemanske RF Jr, Sampson HA, Weiss ST, et al. Atopic dermatitis and asthma: Parallels in the evolution of treatment. Pediatrics. 2003;111(3):608-16.

Eichenfield LF, Tom WL, Berger TG, Krol A, Paller AS, Schwarzenberger K, et al. Guidelines of care for the management of atopic dermatitis: section 2. Management and treatment of atopic dermatitis with topical therapies. J Am Acad Dermatol. 2014a;71(1):116-32.

Eichenfield LF, Tom WL, Chamlin SL, Feldman SR, Hanifin JM, Simpson EL, et al. Guidelines of care for the management of atopic dermatitis: section 1. Diagnosis and assessment of atopic dermatitis. J Am Acad Dermatol. 2014b;70(2):338-51.

Ellis CN, Mancini AJ, Paller AS, Simpson EL, Eichenfield LF. Understanding and managing atopic dermatitis in adult patients. Semin Cutan Med Surg. 2012;31(3 Suppl):S18-22.

Hanifin JM, Reed ML; Eczema Prevalence and Impact Working Group. A population-based survey of eczema prevalence in the United States. Dermatitis. 2007;18(2):82-91.

IBGE - Instituto Brasileiro de Geografia e Estatística. 2016. Available from: https://ww2.ibge.gov.br/home/estatistica/indicadores/ trabalhoerendimento/pme_nova/pme_201602tm_02.shtm.

Illi S, von Mutius E, Lau S, Nickel R, Grüber C, Niggemann B, et al. The natural course of atopic dermatitis from birth to age 7 years and the association with asthma. J Allergy Clin Immunol. 2004;113(5):925-31.

Nutten S. Atopic dermatitis: Global epidemiology and risk factors. Ann Nutr Metab. 2015;66 Suppl 1:8-16.

Sánchez J, Páez B, Macías A, Olmos C, de Falco A. Atopic dermatitis guideline. Position paper from the Latin American Society of Allergy, Asthma and Immunology. Rev Alerg Mex. 2014;61(3):178-211.

Solé D, Wandalsen GF, Camelo-Nunes IC, Naspitz CK. Prevalência de sintomas de asma, rinite e eczema atópico entre crianças e adolescentes brasileiros identificados pelo International Study of Asthma and Allergies (ISAAC): fase 3. J Pediatr (Rio J). 2006;82(5):341-6.

Yamada E, Vanna AT, Naspitz CK, Solé D. International Study of Asthma and Allergies in Childhood (ISAAC): Validation of the written questionnaire (eczema component) and prevalence of atopic eczema among Brazilian children. J Investig Allergol Clin Immunol. 2002;12(1):34-41. 